\title{
Subthreshold Depression Needs A Prime Time In Old Age Psychiatry? A Narrative Review Of Current Evidence
}

This article was published in the following Dove Press journal: Neuropsychiatric Disease and Treatment

\author{
Marina Maria Biella' \\ Marcus Kiiti Borges (DD' \\ Jason Strauss ${ }^{2}$ \\ Sivan Mauer (D) ${ }^{3}$ \\ José Eduardo Martinelli (iD) ${ }^{4}$ \\ Ivan Aprahamian (1D) ${ }^{1,4}$ \\ 'Department and Institute of Psychiatry, \\ Faculty of Medicine, University of São \\ Paulo, São Paulo, Brazil; ${ }^{2}$ Geriatric \\ Psychiatry, Cambridge Health Alliance, \\ Harvard Medical School, Boston, MA, \\ USA; ${ }^{3}$ Department of Psychiatry, Tufts \\ Medical Center, Tufts University Scholl of \\ Medicine, Boston, MA, USA; ${ }^{4}$ Geriatrics \\ \& Psychiatry Division, Department of \\ Internal Medicine, Faculty of Medicine of \\ Jundiaí, Jundiaí, Brazil
}

Correspondence: Ivan Aprahamian Group of Investigation on Multimorbidity and Mental Health in Aging (GIMMA), Internal Medicine Department, Faculty of Medicine of Jundiaí, Jundiaí, Brazil Email ivan.aprahamian@gmail.com

\begin{abstract}
This study aims to carry out a narrative review, aiming to update the literature on subsyndromic depression (SD), which is the most prevalent depressive disorder in older adults, and no formal guidelines or consensus are dedicated to this topic. We carried out an electronic search for articles on SD. Relevant articles were retrieved from Pubmed, EMBASE and Web of Science using the search terms "subthreshold depression," "prevalence," "treatment" and "older adults" in several combinations. Original articles in English were included from inception to 1st March 2019. No clear consensus exists in the literature on its nosologic classification, diagnostic tools, causes, course, outcomes or management. SD diagnosis should base in depressive symptoms scales and DSM criteria. Treatment relies mainly on collaborative care and psychotherapy. SD is relevant in clinical practice and research in geriatric psychiatry. Given the negative outcomes and potential benefits of treatment, we recommend brief psychotherapy as first-line treatment and use of psychotropic agents in cases with greater severity and/or functional impairment in association with psychotherapy. SD can precede major depressive disorder, but it also may consist of a primary depressive disorder in older adults. Furthermore, adequate treatment of SD can prevent or reduce negative outcomes associated with depressive symptoms such as worsening of clinical comorbidities, loss of functionality, increased demand for health services, and increased mortality.
\end{abstract}

Keywords: subthreshold depression, prevalence, treatment, depressive symptoms, older adults

\section{Introduction}

Depressive disorders remain highly prevalent, resulting in disability, increased morbimortality and high health costs. ${ }^{1}$ Depression encompasses emotional, cognitive, somatic, perceptual and behavioral symptoms despite the availability of a number of effective therapies, biological and otherwise. Almost $14 \%$ of individuals aged over 55 exhibit a depressive syndrome, of which only $2 \%$ are major depressive disorder (MDD). ${ }^{2}$ On the other hand, many older persons affected by depression do not meet the criteria for an MDD (mostly according to the Diagnostic and Statistical Manual of Mental Disorders 5th edition, DSM-5, or International Classification of Diseases 10th edition), having in fact subsyndromic or subthreshold depression (SD).

Defining SD poses a challenge owing to the heterogeneity of data on definitions for the condition. Conceptual definitions of SD are: 1) a disorder on its own, as considered by DSM-5; 2) a continuum with MDD; and 3) a combination of residual 
symptoms of depression. The most widely accepted definition in the scientific community, described in DSM-5, is the presence of two or more concurrent symptoms of depressive disorder, one of which is depressed mood, present most or all of the time for at least 2 weeks. The symptoms must cause dysfunction and negatively impact the individual's life and they may never have met the criteria for MDD or dysthymia. ${ }^{3,4}$

A second approach centers on the notion that depressive symptoms considered subthreshold are part of the longitudinal continuum of MDD, i.e., it is a transient phenomenon, where each level of symptomatology is a representation of intensity, stage and severity of MDD. ${ }^{5,6}$ Lastly, the third group characterizes SD as residual symptoms of a depressive disorder, in order words, incomplete remission. $^{7}$

SD is attracting increased attention of the scientific community, not only for its higher prevalence relative to MDD, but also owing to its impact on negative outcomes in later life. ${ }^{8-11}$ Older adults with SD are at greater risk of worsening clinical comorbidity, functional decline, greater demand for healthcare services and even increased mortality. ${ }^{9-11}$ This article provides a narrative review of the diagnostic concepts and associated clinical condition, risk factors, epidemiology, prognosis and treatment options for older patients with SD based on the best and updated evidence from the current literature.

\section{Methods}

This study involved a qualitative integrative review of the literature based on an electronic search for scientific articles focusing on SD. These articles were retrieved from the PubMed, EMBASE and Web of Science databases searched from inception through 1st March 2019 using the following medical subject heading [MeSH Terms] and search terms: ("subthreshold OR minor depression") AND ("prevalence" OR "treatment" OR “older adults"). This initial search retrieved 770 articles for abstract analysis. In addition, the study included a manual review of related terms and citations drawn from the reference lists of the articles selected. Original articles in English were included without limits on year of publication.

\section{Results}

\section{Epidemiology}

The prevalence of SD is higher than for MDD and dysthymia, affecting around $10 \%$ of community-dwelling elderly,
$20 \%$ of primary care patients, and up to $30 \%$ of hospitalized patients and nursing home residents. ${ }^{11-13}$ Moreover, $8-16 \%$ of older adults present clinically significant depressive symptoms (CSDS), a term also used in the literature to refer to $\mathrm{SD} .^{14}$

By comparison, MDD affects $1-4 \%$ of communitydwelling elderly, $5-10 \%$ of primary care patients and $10-12 \%$ of hospitalized older adults and nursing home residents. ${ }^{1,14}$ MDD rates can be as high as $37 \%$ in older ICU patients. ${ }^{6}$ In contrast, dysthymia affects around $2 \%$ of the elderly population. ${ }^{3}$ Similar rates can be found in middle-income countries. In a systematic review investigating the prevalence of depressive morbidity in Brazilian older adults, the authors found a rate of over $7 \%$ for MDD, $26 \%$ for CSDS and 3.3\% for dysthymia. ${ }^{13}$ The Pietà study showed that $26.5 \%$ of community-dwelling individuals aged $75+$ years have had CSDS. ${ }^{15}$

\section{Risk Factors}

The risk factors for the occurrence of SD are essentially the same as for depressive disorders. SD can be the cause or consequence of MDD, or both. The main factors established in the literature are given in Box 1. ${ }^{11,16-18}$

\section{Diagnosis}

Depressive disorders in older age have been under-diagnosed for several reasons: under-reporting by the patient or lack of active search by the health team, depressive picture different to younger adults, symptoms that resemble organic disturbances, polypharmacy, multimorbidity, depressive symptoms considered factors inherent to the aging process, stigma and fear of diagnosis of mental disorder. Diagnosing SD can be challenging as issues addressed during anamnesis such as depressed mood or loss of interest or pleasure can have a low impact on patient discourse and may be absent altogether. ${ }^{19-21}$

Current and most commonly cited operational definitions of SD are 1) DSM-5 criteria for SD and/or 2) scoring above a cut-off of a screening tool for depression. Formal, structural and objective diagnoses of depressive disorders can be established using the International Classification of Diseases (ICD) and/or Diagnostic and Statistical Manual of Mental Disorders (DSM). The diagnostic criteria for SD according to the DSM-5 appear in Box 2. Within the ICD-10 subthreshold depression is only classified for research purposes as a depressive disorder "not otherwise specified." However, as the diagnostic criteria have not been clear, this classification is rarely used. 
Box I Risk Factors For Subthreshold Depression

\begin{tabular}{|l|l|l|}
\hline Female gender & Childhood poverty, abuse or neglect & Widow/widower, single and divorced \\
\hline $\begin{array}{l}\text { Low educational } \\
\text { level }\end{array}$ & $\begin{array}{l}\text { Poor socioeconomic level or social support or environment (both } \\
\text { socially and/or economically) }\end{array}$ & $\begin{array}{l}\text { Personal or family history of depression and/or other } \\
\text { psychiatric disorder }\end{array}$ \\
\hline $\begin{array}{l}\text { Neurotic } \\
\text { personality traits }\end{array}$ & Physical disability & Functional decline \\
\hline $\begin{array}{l}\text { Nursing home } \\
\text { resident }\end{array}$ & Negative life events & Visual/hearing deficit \\
\hline Advanced age & Cognitive decline & Loneliness \\
\hline Insomnia & $\begin{array}{l}\text { Clinical comorbidities } \\
\text { e.g. Stroke, heart diseases, Parkinson's disease, chronic kidney } \\
\text { disease, diabetes, cancer, etc. }\end{array}$ & Chronic uncontrolled pain \\
\hline
\end{tabular}

Box 2 Diagnostic Criteria For Subthreshold Depression According To DSM-5

"Depressed mood and at least one of the other eight symptoms of a
Major Depressive episode, associated with clinically significant
distress or deficit lasting at least 2 weeks, in individuals not meeting
criteria for any other Depressive or Bipolar Disorder, and currently
exhibiting no active or residual criteria for any Psychotic Disorder,
and does not meet the criteria of mixed Anxiety or symptoms of
Depressive Disorder."

By the way, minor depression is a diagnosis no longer classified in the DSM-5. Other validated instruments with established cut-off scores have shown good accuracy for detecting clinically relevant depressive symptoms. Therefore, these scales are useful, providing a comprehensive assessment of depressive symptomatology, covering a range of different symptoms and allowing a broader diagnosis of SD. The scales validated for $\mathrm{SD}$ are: ${ }^{22}$

- Geriatric Depression Scale (GDS) - 30-item; ${ }^{23-25}$

- Center for Epidemiologic Studies Depression Scale (CES-D) - 20-item; ${ }^{26-31}$

- Hamilton Depression Rating Scale (HAM-D) 17 -item; ${ }^{32}$

- Patient Health Questionnaire (PHQ-9); ${ }^{21}$

- EURO-D - 12 item. $^{33}$

Although depression scales are useful in clinical practice, we emphasized the paradox of not having an established cut-off for any of these instruments. Cut-off for clinically relevant depressive symptoms varies between countries, populations and settings (e.g., primary care, communitydwelling). Lavretsky and Kumar recommended a 12-point cut-off in GDS 30 items for SD, ${ }^{24}$ whereas Watson and colleagues determined a cut-off of 9 points. ${ }^{25}$ The diagnosis of SD using the PHQ-9 is performed by 2 to 4 items, one of them must be anhedonia or sadness. We used the cut-off $\geq 10$ points to define clinically significant depression and indicate the need for treatment. Lastly but not less important, an interview with the caregiver or family informant can be necessary in cases of depression with cognitive symptoms and/or under-reporting of depressive symptoms by the elder. ${ }^{24}$

As seen, there is the possibility that the diagnosis can be made by scales of symptoms or categorical classifications. The criticism of this second modality, exemplified by the DSM, is that it was not specially adapted for depression among older adults, but only adequate to a certain extent in older age groups. The relatively low prevalence rates of major depression in seniors, compared with less severe variants of depressive disorders, may support this hypothesis. ${ }^{26}$

CES-D cut-off scores showed the greatest reference variation among depression scales, varying from $\geq 16$ points for $\operatorname{DS}^{26,29}$ with $100 \%$ sensitivity and $88 \%$ specificity, between 8 and $15^{27,31}$ and $\geq 9$ points in other studies. ${ }^{28,30}$ In several European studies, especially the SHARE study, the EURO-D was used to measure depressive symptoms (used cut-off 4 points on a 12-item scale). ${ }^{33}$ Highest percentages were observed in Southern Europe (35\%), followed by Central and Eastern Europe (32\%), Western Europe $(26 \%)$ and lowest in Scandinavia $(17 \%) .{ }^{34}$ In the Netherlands, a cut-off of 16 points in CES-D used to identify clinically relevant depressive symptoms (Longitudinal Aging Study Amsterdam, LASA), ${ }^{35}$ whereas in Italy a cutoff of 20 points identifies clinically relevant depressive 
symptoms (InChianti study). ${ }^{36}$ Finally, an interview with the caregiver or family informant can be necessary in cases of depression with cognitive symptoms and/or underreporting of depressive symptoms by the elder. ${ }^{37}$

We recommend that older people present depressive symptoms that include somatic symptoms, subjective complaints of memory and cognitive deficits with greater prevalence in relation to younger ones. This means that instruments or scales of symptoms that consider this particularity are often used to support the diagnosis. ${ }^{38}$

However, one criticism of this is the possibility of considering a somatic symptom, when in reality it is a symptom of a current organic disease. For example, symptoms that commonly occur after an acute myocardial infarct, including fatigue, loss of energy, changes in sleep patterns and changes in appetite, they may be misinterpreted by health care professionals or researchers and misidentified. $^{39}$

Finally, we recommend that the diagnosis of SD be based on:

1. Diagnostic criteria (using a psychiatric interview to establish minor depression according to DSM-IV, or a depressive episode with insufficient symptoms according to DSM-5)

2. Scoring above a cut-off on validated screening scales.

Ideally, a combination of the two, like done in LASA, ${ }^{35} \mathrm{i}$. e. minor depression is defined as a score above the cut-off on the CES-D $(\geq 16)$ and not meeting the criteria for an MDD (based on the DIS).

\section{Clinical Condition And Analysis Of Symptoms}

Generally, SD can involve the same symptoms as established for MDD, as depicted in Box 3, with the differential

\section{Box 3 Potential Depressive Symptoms In SD}

\begin{tabular}{|l|l|}
\hline $\begin{array}{l}\text { Depressed mood and/or diminished } \\
\text { interest or pleasure in usual activities }\end{array}$ & $\begin{array}{l}\text { Feelings of worthlessness } \\
\text { or excessive guilt }\end{array}$ \\
\hline $\begin{array}{l}\text { Decreased concentration and difficulty } \\
\text { making decisions }\end{array}$ & Fatigue or loss of energy \\
\hline Psychomotor retardation or agitation & Insomnia or Hypersomnia \\
\hline $\begin{array}{l}\text { Weight loss or gain and increase or } \\
\text { decrease in appetite }\end{array}$ & $\begin{array}{l}\text { Thoughts of death and } \\
\text { suicidal ideation }\end{array}$ \\
\hline
\end{tabular}

being: the number, duration, severity and prevalence of symptoms, as well as the exclusion criteria.

Analysis of symptoms should take into account the specificities of depressive symptoms in older adults, as shown in Table 1 (Fogel et al, 2006; Kroenke, 2006; Pietrzak et al, 2013; Vaccaro et al, 2017). ${ }^{12,40-42}$

As mentioned before, SD symptoms should be classified into three groups: the first group comprises prodromal symptoms of MDD; the second, residual symptoms of MDD; and lastly, in the third group, symptoms are regarded as inherent to SD. It is important to emphasize that for the first two hypotheses, although symptoms are similar, the conditions are different to the third. ${ }^{43}$ Consequently, different types of intervention would be required (e.g., early psychotherapeutic intervention to prodromal MDD or watchful waiting strategy; change or addition of antidepressant or augmentation add-on therapy if residual symptoms; treatment of SD is discussed further). To make this distinction to both clinical and research settings, in-depth anamnesis is needed, besides an investigation of the history of previous depressive episodes that characterize MDD, a qualitative and quantitative assessment of symptoms present, the use of categorical scales and classifications, and previous and current use or otherwise of antidepressants, as well as serial reassessments of the patient. Furthermore, a time-window should be considered for which SD is prodromal of MDD (although prodromal can still be seen as a risk factor, but in that case not a causal risk factor).

An important aspect of the evolution of symptoms is differentiating which depressive symptoms or risk factors are most implicated in the progression of SD to MDD. Evidence in the literature is equivocal, but potentially important aspects are listed below. ${ }^{44-46}$

- Feelings of guilt or worthlessness;

- Poor concentration;

- Number of depressive symptoms;

- Family history of depression;

- Negative life events;

- Personality characteristics;

- Chronic diseases;

- Weight or appetite changes;

- Suicidal ideation;

- Sleep disturbance.

\section{Rate Of Conversion From SD To MDD}

The heterogeneity of studies on the subject, as outlined earlier, hampers the comparison of SD and MDD, 
Table I Clinical Characteristics Of Depressive Symptoms In Older Adults

\begin{tabular}{|c|c|}
\hline Symptoms & Clinical Characteristics \\
\hline Affective symptoms & $\begin{array}{l}\text { Depressed mood and loss of interest or pleasure may not have a major impact on the discourse of older patients. In } \\
\text { clinical practice, it is not uncommon for older adults to be misdiagnosed with apathy instead of sadness and } \\
\text { anhedonia. }\end{array}$ \\
\hline Somatic symptoms & $\begin{array}{l}\text { Often these symptoms are reported by older patients, and may be the sole or main complaint. These symptoms are } \\
\text { often neglected because they may be associated with organic factors or patients become labelled "chronic } \\
\text { complainers" by the health professional. Examples in clinical practice include reports of non-specific pain, fatigue, } \\
\text { feeling of dyspnea and chest pain, dizziness, heaviness in the legs, malaise, among other symptoms. }\end{array}$ \\
\hline Cognitive symptoms & $\begin{array}{l}\text { A common complaint that may characterize dementia syndrome of depression, formerly called "pseudodementia" in } \\
\text { moderate-to-severe depression. Cognitive complaints invariably involve memory and can be the reason for the } \\
\text { medical visit. }\end{array}$ \\
\hline Psychotic symptoms & These are not typical of SD. \\
\hline $\begin{array}{l}\text { Suicidal ideation/attempted } \\
\text { suicide }\end{array}$ & Key differential between MDD and SD, where these symptoms are severe and characteristic of MDD. \\
\hline Anxiety symptoms & $\begin{array}{l}\text { Such symptoms are common in depressed patients. The two psychiatric comorbidities may be associated (depressive } \\
\text { and anxiety disorder are often comorbid and diagnostic stability over time is limited) }\end{array}$ \\
\hline Others & $\begin{array}{l}\text { Social withdrawal, poor adherence to medications and medical visits, low self-care, abuse of alcohol or sedatives (e.g. } \\
\text { benzodiazepines). }\end{array}$ \\
\hline
\end{tabular}

detracting from their results. ${ }^{47}$ Notably, four studies showed that SD patients had persistent depressive symptoms during a 12-month follow-up, where one-third to a half of participants reported moderate functional impairment and at least $10-20 \%$ evolved to MDD. ${ }^{4-51}$ The CASPER study found SD to MDD conversion rates of $28-41 \%$ over 12 months, ${ }^{46}$ whereas other studies suggested lower rates of between $10 \%$ and $20 \%{ }^{52,53}$ Some prospective studies indicated that $10 \%$ of adults with SD developed MDD every year, with similar rates confirmed among older adults. ${ }^{54-56}$

A study conducted in the Netherlands through stepped intensive care in a randomized controlled design for the prevention of depression and anxiety in older adults with clinically relevant depressive symptoms $(\mathrm{CESD} \geq 16)$ who did not meet the criteria for an MDD. ${ }^{57}$ It showed that the intervention halved the incidence in 12 months of both depressive and anxious disorders. ${ }^{57}$

\section{Prognosis}

In addition to not fulfilling the criteria for an MMD, SD should also not be associated with little, low or no impact on negative outcomes. In older adults, the depressive disturbance not only adds to the burden of other chronic diseases (e.g., angina, arthritis, asthma and diabetes) increasing morbimortality, but is also an important factor that exacerbates existing comorbidities. ${ }^{58,59}$ Factors contributing to increased morbimortality are given in Box $4 .^{3-7}$

The literature clearly shows that depressive disorders increase mortality rates. A recent meta-analysis observed a relative risk of 1.58 associated with MDD and 1.33 with SD. ${ }^{60}$ Both conditions were associated with significantly higher risk of mortality compared with non-depressed samples. ${ }^{60}$ Although the risk of death is higher in MDD, the prevalence of the disorder is lower than for SD. Moreover, remission rates for SD are highly heterogeneous, ranging from $20 \%$ to $50 \%$ according to some authors. ${ }^{61-64}$

\section{Box 4 Negative Outcomes Associated With SD}

\begin{tabular}{|l|l|l|}
\hline Worse quality of life & Higher health costs & $\begin{array}{l}\text { Functional } \\
\text { decline }\end{array}$ \\
\hline $\begin{array}{l}\text { Increased risk of } \\
\text { cognitive impairment } \\
\text { and dementia }\end{array}$ & $\begin{array}{l}\text { Worse evolution of } \\
\text { clinical } \\
\text { comorbidities }\end{array}$ & $\begin{array}{l}\text { Greater demand } \\
\text { for health } \\
\text { services }\end{array}$ \\
\hline Greater mortality & $\begin{array}{l}\text { Greater } \\
\text { hospitalization }\end{array}$ & $\begin{array}{l}\text { Increased risk for } \\
\text { major depression } \\
\text { and dysthymia }\end{array}$ \\
\hline $\begin{array}{l}\text { Greater dependence on } \\
\text { alcohol, illicit drugs and } \\
\text { abuse of medications (e.g. } \\
\text { sleeping pills, pain killers, } \\
\text { etc.) }\end{array}$ & $\begin{array}{l}\text { Emergence or } \\
\text { exacerbation of } \\
\text { other psychiatric } \\
\text { disorders }\end{array}$ & $\begin{array}{l}\text { Increased risk of } \\
\text { suicide }\end{array}$ \\
\hline
\end{tabular}




\section{Differential Diagnosis Organic Diseases}

In older patients, a symptom can often have more than one underlying cause. For example, a feeling of tiredness, fatigue and breathlessness can be secondary to a lung or heart disease, or may be of psychogenic origin. Therefore, investigating symptoms from both a psychiatric and somatic perspective is essential for the differential diagnosis of SD.

Older persons can have multiple comorbidities, yet similar symptoms. In addition, a psychiatric sign or symptom can be a prodromal state of somatic diseases such as Parkinson's disease, dementia syndromes, hypothyroidism, cancer, among others. Some examples of symptoms present in organic disturbances of older patients that can resemble depressive disorders are given in Box 5 .

The attending physician should assess symptoms and the clinical examination, order the pertinent laboratory tests and imaging scans to rule out clinical diseases, and determine whether the constellation of signs and symptoms indicates an organic syndrome. The physician should also be alert to any exaggeration, atypical feature in patient reports, and to whether there is response to therapy instituted, motivation and adherence to treatment. Finally, regular reassessment of the patient is essential to assess the spectrum of symptoms and check for emergence of new symptoms, given that the health professional may be dealing only with a clinical or psychiatric disease or both. In $\mathrm{SD}$, watchful waiting is an essential first step in cases without functional decline or severity, and in case of persistent symptoms to institute treatment (see below).

\section{Normal Sadness Inherent To The Human Condition}

The context of old age is permeated by a host of different biological, psychological, social and financial changes. It is often hard to distinguish sadness secondary to these

Box 5 Organic Disturbances With Similar Symptomatology To Depressive Disorders

\begin{tabular}{|l|l|}
\hline $\begin{array}{l}\text { Cardiopulmonary } \\
\text { diseases }\end{array}$ & $\begin{array}{l}\text { Tiredness, fatigue, breathlessness, palpitation, } \\
\text { weight loss, chest tightness and pain }\end{array}$ \\
\hline $\begin{array}{l}\text { Dyspeptic } \\
\text { diseases }\end{array}$ & $\begin{array}{l}\text { Chest pain, changes in appetite. Weight loss and } \\
\text { distorted sense of taste. }\end{array}$ \\
\hline Frailty syndrome & $\begin{array}{l}\text { Fatigue, limb weakness, loss of appetite and } \\
\text { weight loss }\end{array}$ \\
\hline $\begin{array}{l}\text { Oncologic } \\
\text { diseases }\end{array}$ & $\begin{array}{l}\text { Weakness, reduced appetite, weight loss, apathy } \\
\text { and pains }\end{array}$ \\
\hline
\end{tabular}

changes from a depressive state. Health professionals need to differentiate a disorder of adjustment/coping (e.g., an elder who loses a family member or close friend, their retirement day, or being diagnosed with a serious illness) from a case of SD. Reassessment based on established diagnostic criteria, as well as subsequent monitoring of the negative impacts on the patient's life, are important to prevent under diagnosis of SD. Furthermore, accurate early diagnosis of SD is critical to avert unnecessary, costly and stigmatizing treatment in the future.

\section{Treatment}

The aim of treatment for SD is to reduce, or prevent, the negative outcomes associated with this depressive condition, and also to act as a powerful instrument for preventing MDD. ${ }^{65}$ The benefits in the literature of SD treatment are well established and associated with improved prognosis. However, there is lack of consensus on the efficacy of different therapeutic strategies. ${ }^{66,67}$ We recommend following a checklist to improve the approach and interventions:

(I) Clarity after assessment of patient, whether symptoms presented are residual after MDD, or exhibit symptomatology that does not fulfill criteria for MDD;

(II) Assess symptoms presented in a qualitative and quantitative manner, determining the magnitude of the negative impact on the patient's life, such as on: professional, social, affective, personal and financial domains, and also the distress caused and decline in quality of life.

(III) Conduct a full-personalized assessment for each patient to conclude which treatment will be most beneficial;

(IV) Reassessing and monitoring the patient are also crucial.

"Watchful waiting": this does not constitute a total absence of treatment, but entails systematic surveillance comprising assessment of symptoms, their course and impact. Although suggested in some guidelines, this may be insufficient, with questionable expectancy and risks inherent to negative outcomes. ${ }^{68}$ Although not highly recommended in the literature, this approach may suit patients who have good social support, no personal or family history of depressive disorder, and that refuse pharmacological and/ or psychotherapeutic treatment even after the risks and available treatment options have been explained. ${ }^{68}$ 
"Patient preferences": the literature on this topic is scarce and controversial. Some studies have failed to show favorable outcomes, whereas others report positive outcomes. ${ }^{69,70}$ In clinical practice, educating the patient about their illness and treatment options is of primary importance, so that both physician and patient can take a shared decision. A recent review showed benefits in terms of adherence, treatment satisfaction and outcomes. ${ }^{71}$

Psychotherapy: currently, psychological therapies, particularly brief ones, are the interventions showing the strongest evidence as first-line treatment. ${ }^{72,73}$ This approach is especially beneficial in older adults because it allows many psychic aspects and their functioning to be addressed. The CASPER study confirmed the merit of SD treatment in an older adults' group enrolled in a structured program with psychological support and a behavioral approach. ${ }^{46}$ The group was shown to have reduced depressive symptoms, as measured by the PHQ-9, after a fourmonth intervention compared to the group receiving usual treatment for depressive disorders. ${ }^{46}$

Another important study was a meta-analysis that included seven studies and involved 700 individuals. $^{74}$ The risk of developing MDD in individuals that underwent the psychotherapeutic intervention was $30 \%$ lower. The study concluded that psychological treatment had significant effects and benefits on SD and that this intervention can reduce major depression or prevent its onset.

A meta-analysis of brief psychological therapies (typically 8 sessions or fewer) showed that cognitive behavior therapy (13 studies), problem-solving therapy (12 studies) and counselling ( 8 studies) all proved effective treatments of depression in primary care. ${ }^{75}$

Phytotherapy: many patients seek phytotherapy alternatives. One of the most clinically popular is St. John's Wort or Hypericumperforatum. However, the efficacy of phytotherapy is controversial, since most studies failed to confirm benefits over placebo in the treatment of MDD or $\mathrm{SD}^{76,77}$

Anti-depressants: Few studies have investigated the effects of pharmacological treatment in older adults with $\mathrm{SD}$, where the majority of trials under-represent older people. ${ }^{78-80}$ A meta-analysis that included 6 clinical trials, with treatment using anti-depressants and placebo, found no advantages of the psychotropic agent over placebo. ${ }^{81}$ By contrast, another study comparing paroxetine with placebo showed the benefit of the anti-depressant in improving depressive symptoms and a positive impact on patients with more severe functional impairment. ${ }^{82}$
The prescription of antidepressants is not recommended as first-line treatment or sole intervention for SD treatment. ${ }^{2,83-85}$ Despite scant literature on controlled trials of psychotropics in older patients, there is evidence of benefits of antidepressant use in SD patients who have more numerous and severe symptoms, and also in older patients with functional impairment and/or suicidal ideation. ${ }^{47,86,87}$

Anti-depressants offer a number of advantages over psychotherapy. The former are immediately available and effects of treatment can be ascertained within a short timeframe (2-3 weeks). Additionally, psychotherapy may not be easily accessible and is often associated with waiting times, while assessing results also takes longer. Nevertheless, use of these drugs in older patients carries a higher risk of adverse events due to multiple medical comorbidities and drug-drug interactions in the case of polypharmacy. ${ }^{2}$ The choice of pharmacological class should take into account the following factors:

- contraindication for medications;

- potential undesirable adverse effects, such as weight gain with tricyclic antidepressants in patients with metabolic syndrome, or adverse effects that benefit certain patients, such as when using mirtazapine to enhance appetite and sleepiness in patients with inverse symptomatology;

- access and cost of the treatment;

- previous personal or family outcomes after antidepressant use.

In older adults, starting on lower doses with gradual increase is recommended, as is monitoring of side effects. In this age group, serotonin reuptake inhibitors (SSRIs) remain the first line of drug treatment. ${ }^{1,16}$

Others: The following elements are also important in an integral approach: ${ }^{88}$

(a) adequate control of clinical comorbidities;

review of medications prescribed. A recent study highlighted depression as a potential adverse effects of prescription medications. ${ }^{89}$ Main examples were gastrointestinal agents (omeprazole, ranitidine), anti-hypertensives (metoprolol, atenolol, enalapril), corticosteroids and analgesic agents. (tramadol, hydrocodone)

(b) changes in lifestyle by giving up smoking and alcohol use, going on a healthy diet and engaging in physical activity; 
(c) interventions in social and family spheres to promote conflict resolution, social support and reintegration of the elder in different aspects of their life.

\section{Conclusion}

After ruling out organic causes and excluding the possibility of a diagnosis of MDD, dysthymia and coping/adjustment to negative life events, we recommend that patients be defined as SD. Despite the dearth of studies in the literature, disease management should be based on epidemiological evidence, negative outcomes and potential benefits of treatment.

We conclude that brief psychotherapy remains the firstline treatment approach, especially in frail older adults who are more vulnerable to multiple comorbidities. Psychotropic agents (especially SSRIs given the number of trials and clinical safety) prescribed in association with psychotherapy or as monotherapy can be recommended for patients with numerous or more severe symptoms and functional impairment. Further studies should explore the clinical course of older adults with depressive symptoms or SSD to better characterize this condition. Systematic reviews of current evidence are also needed to shed light on future study designs, especially to clinical trials.

\section{Acknowledgments}

Prof. Aprahamian receives a National public grant level 2 from the National Council for Scientific and Technological Development (Ministry of Science, Technology, Innovation and Communications, Brazil).

\section{Disclosure}

The authors report no conflicts of interest in this work.

\section{References}

1. Taylor WD. Clinical practice. Depression in the elderly. $N$ Engl J Med. 2014;371:1228-1236. doi:10.1056/NEJMcp 1402180

2. Kok RM, Reynolds CF 3rd. Management of depression in older adults: a review. JAMA. 2017;317:2114-2122. doi:10.1001/jama.2017.5706

3. Alexopoulos GS. Depression in the elderly. Lancet. 2005;365:1961-1970.

4. Blazer DG. Depression in late life: review and commentary. $J$ Gerontol A Biol Sci Med Sci. 2003;58:249-265.

5. Adams KB, Matto HC, Sanders S. Confirmatory factor analysis of the geriatric depression scale. Gerontologist. 2004;44:818-826.

6. Jackson JC, Pandharipande PP, Girard TD, et al. Depression, posttraumatic stress disorder, and functional disability in survivors of critical illness in the BRAIN-ICU study: a longitudinal cohort study. Lancet Respir Med. 2014;2:369-379.

7. American Psychiatric Association. Practice guideline for the treatment of patients with major depressive disorder (revision). Am J Psychiatry. 2000;157:1-45.
8. Judd LL, Rapaport MH, Paulus MP, Brown JL. Subsyndromal symptomatic depression: a new mood disorder? J Clin Psychiatry. 1994;55:18-28.

9. Cuijpers P, Smit F. Subthreshold depression as a risk indicator for major depressive disorder: a systematic review of prospective studies. Acta Psychiatr Scand. 2004;109:325-331.

10. Adams KB, Moon H. Subthreshold depression: characteristics and risk factors among vulnerable elders. Aging Ment Health. 2009;13:682-692. doi:10.1080/13607860902774501

11. Meeks TW, Vahia IV, Lavretsky H, Kulkarni G, Jeste DV. A tune in "a minor" can "b major": a review of epidemiology, illness course, and public health implications of subthreshold depression in older adults. J Affect Disord. 2011;129:126-142.

12. Vaccaro R, Borrelli P, Abbondanza S, et al. Subthreshold depression and clinically significant depression in an Italian population of 70 74-year-olds: prevalence and association with perceptions of self. Biomed Res Int. 2017;2017:3592359. doi:10.1155/2017/3592359

13. Barcelos-Ferreira R, Izibick R, Steffens DC, Bottino CM. Depressive morbidity and gender in community-dwelling Brazilian elderly: systematic review and meta-analysis. Int Psychogeriatr. 2010;22:712726. doi:10.1017/S1041610210000463

14. Koenig HG, George LK, Peterson BL, Pieper CF. Depression in medically ill hospitalized older adults: prevalence, characteristics, and course of symptoms according to six diagnostic schemes. Am J Psychiatry. 1997;154:1376-1383. doi:10.1176/ajp.154.10.1376

15. Dias FLC, Teixeira AL, Guimarães HC, et al. Prevalence of late-life depression and its correlates in a community-dwelling low-educated population aged $75+$ years: the Pietà study. $J$ Affect Disord. 2019;242:173-179. doi:10.1016/j.jad.2018.08.012

16. Cepoiu M, McCusker J, Cole MG, Sewitch M, Ciampi A. Recognition of depression in older medical inpatients. J Gen Intern Med. 2007;22:559-564. doi:10.1007/s11606-006-0085-0

17. Covinsky KE, Cenzer IS, Yaffe K, O’Brien S, Blazer DG. Dysphoria and anhedonia as risk factors for disability or death in older persons: implications for the assessment of geriatric depression. Am J Geriatr Psychiatry. 2014;22:606-613. doi:10.1016/j.jagp.2012.12.001

18. Yesavage JA, Brink TL, Rose TL, et al. Development and validation of a geriatric depression screening scale: a preliminary report. $J$ Psychiat Res. 1982;17:37-49.

19. Radloff LS. The CES-D scale: a self-report depression scale for research in the general population. App Psychol Meas. 1977;1:385401. doi:10.1177/014662167700100306

20. Hamilton M. A rating scale for depression. $J$ Neurol Neurosurg Psychiatry. 1960;23:56-62. doi:10.1136/jnnp.23.1.56

21. Kroenke K, Spitzer RL, Williams JB. The PHQ-9: validity of brief depression severity measure. J Gen Intern Med. 2001;16:606-613. doi:10.1046/j.1525-1497.2001.016009606.x

22. Davison TE, McCabe MP, Mellor D. An examination of the "gold standard" diagnosis of major depression in aged-care settings. Am J Geriatr Psychiatry. 2009;17:359-367. doi:10.1097/JGP.0b013e318190b901

23. Crum RM, Cooper-Patrick L, Ford DE. Depressive symptoms among general medical patients: prevalence and one-year outcome. Psychosom Med. 1994;56:109-117. doi:10.1097/00006842-199403000-00006

24. Lavretsky H, Kumar A. Clinically significant non-major depressionold concepts, new insights. Am J Geriatr Psychiatry. 2002;10:239255.

25. Watson LC, Lewis CL, Kistler CE, Amick HR, Boustani M. Can we trust depression screening instruments in healthy 'old-old' adults? Int J Geriatr Psychiatry. 2004;19:278-285. doi:10.1002/gps.1082

26. Beekman AT, Deeg DJ, Van Tilburg T, Smit JH, Hooijer C, Van Tilburg W. Major and minor depression in later life: a study of prevalence and risk factors. $J$ Affect Disord. 1995;36:65-75. doi:10.1016/0165-0327(95)00061-5

27. Cohen CI, Magai C, Yaffee R, Walcott-Brown L. Racial differences in syndromal and subsyndromal depression in an older urban population. Psychiat Serv. 2005;56:1556-1563. 
28. Hybels CF, Blazer DG, Pieper CF. Toward a threshold for subthreshold depression: an analysis of correlates of depression by severity of symptoms using data from an elderly community sample. Gerontologist. 2001;41:357-365.

29. Maercker A, Forstmeier S, Enzler A, et al. Adjustment disorders, posttraumatic stress disorder, and depressive disorders in old age: findings from a community survey. Compr Psychiatry. 2008;49:113120.

30. Morrow-Howell H, Proctor E, Choi S, et al. Depression in public community long-term care: implications for intervention development. J Behav Health Serv Res. 2008;35:37-51.

31. Vahia IV, Meeks TW, Thompson WK, et al. Subthreshold depression and successful aging in older women. Am J Geriatr Psychiatry. 2010;18:212-220.

32. King-Kallimanis B, Gum AM, Kohn R. Comorbidity of depressive and anxietydisorders for older Americans in the national comorbidity survey-replication. Am J Geriatr Psychiatry. 2009;17:782-792.

33. Brailean A, Comijs HC, Aartsen MJ, et al. Late-life depression symptom dimensions and cognitive functioning in the Longitudinal Aging Study Amsterdam (LASA). J Affect Disord. 2016;201:171-178.

34. Prince MJ, Reischies F, Beekman AT, et al. Development of the EURO-D scale - a European, Union initiative to compare symptoms of depression in 14 European centres. $\mathrm{Br} J$ Psychiatry. 1999;174:330-338.

35. Horackova K, Kopecek M, Machů V, et al. Prevalence of late-life depression and gap in mental health service use across European regions. Eur Psychiatry. 2019;57:19-25.

36. Vogelzangs N, Beekman AT, Boelhouwer IG, et al. Metabolic depression: a chronic depressive subtype? Findings from the InCHIANTI study of older persons. J Clin Psychiatry. 2011;72:598-604.

37. Pede VB, Jaiswal SV, Sawant VA. Study of prodromal and residual symptoms of depression. Int Psychiatry J. 2017;26:121-127.

38. Luppa M, Sikorski C, Luck T, et al. Age- and gender-specific prevalence of depression in latest-life - systematic review and metaanalysis. J Affec Disord. 2012;136:212-221.

39. Thombs BD, Ziegelstein RC, Pilote L. Somatic symptom overlap in Beck Depression Inventory-II scores following myocardial infarction. Br J Psychiatry. 2010;197:61-66.

40. Fogel J, Eaton WW, Ford DE. Minor depression as a predictor of the first onset of major depressive disorder over a 15-year follow-up. Acta Psychiatr Scand. 2006;113:36-43.

41. Pietrzak RH, Kinley J, Afifi TO, et al. Subsyndromal depression in the United States: prevalence, course, and risk for incident psychiatric outcomes. Psychol Med. 2013;43:1401-1414.

42. Kroenke K. Minor depression: midway between major depression and euthymia. Ann Intern Med. 2006;144:528-530.

43. Rodríguez MR, Nuevo R, Chatterji S, Ayuso-Mateos JL. Definitions and factors associated with subthreshold depressive conditions: a systematic review. BMC Psychiatry. 2012;12:181.

44. Lyness JM, Heo M, Datto CJ, et al. Outcomes of minor and subsyndromal depression among elderly patients in primary care settings. Ann Intern Med. 2006;144:496-504.

45. Jaffe A, Froom J, Galambos N. Minor depression and functional impairment. Arch Fam Med. 1994;3:1081-1086.

46. Gilbody S, Lewis H, Adamson J, et al. Effect of collaborative care vs usual care on depressive symptoms in older adults with subthreshold depression: the CASPER randomized clinical trial. JAMA. 2017;317:728-737.

47. Ayuso-Mateos JL, Nuevo R, Verdes E, Naidoo N, Chatterji S. From depressive symptoms to depressive disorders: the relevance of thresholds. Br J Psychiatry. 2010;196:365-371.

48. Buntrock C, Ebert DD, Lehr D, et al. Effectof aweb-based guided self-help interventionfor prevention of major depression in adults with subthreshold depression: a randomized clinical trial. JAMA. 2016;315:1854-1863.
49. Broadhead WE, Blazer DG, George LK, et al. Depression, disability days, and days lost from work in a prospective epidemiologic survey. JAMA. 1990;264:2524-2528.

50. Cuijpers P, Beekman A, Smit F, et al. Predicting the onset of major depressive disorder and dysthymia in older adults with subthreshold depression: a community based study. Int $J$ Geriatr Psychiatry. 2006;21:811-818.

51. Schoevers RA, Smit F, Deeg DJ, et al. Prevention of late-life depression in primary care: do we know where to begin? Am J Psychiatry. 2006;163:1611-1621.

52. Kupfer DJ, Frank E, Phillips ML. Major depressive disorder: new clinical, neurobiological, and treatment perspectives. Lancet. 2012;379:1045-1055.

53. Moussavi S, Chatterji S, Verdes E, et al. Depression, chronic diseases, and decrements in health: results from the World Health Surveys. Lancet. 2007;370:851-858.

54. Beekman AT, Deeg DJ, Braam AW, et al. Consequences of major and minor depression in later life: a study of disability, well-being and service utilization. Psychol Med. 1997;27:1397-1409.

55. Hybels CF, Pieper CF, Blazer DG. The complex relationship between depressive symptoms and functional limitations in community-dwelling older adults: the impact of subthreshold depression. Psychol Med. 2009;39:1677-1688

56. Grabovich A, Lu N, Tang W, et al. Outcomes of subsyndromal depression in older primary care patients. Am J Geriatr Psychiatry. 2010;18:227-235.

57. Van't Veer-Tazelaar PJ, van Marwijk HW, van Oppen P, et al. Stepped-care prevention of anxiety and depression in late life: a randomized controlled trial. Arch Gen Psychiatry. 2009;66:297-304.

58. Han L, Mc Cusker J, Cole M, et al. 12-month cognitive outcomes of major and minor depression in older medical patients. Am J Geriatr Psychiatry. 2008;16:742-751.

59. Boyle LL, Porsteinsson AP, Cui X, et al. Depression predicts cognitive disorders in older primary care patients. J Clin Psychiatry. 2010;71:74-79.

60. Cuijpers P, Vogelzangs N, Twisk J, et al. Differential mortality rates in major and subthreshold depression: meta-analysis of studies that measured both. Br J Psychiatry. 2013;202:22-27.

61. Beekman AT, Geerlings SW, Deeg DJ, et al. The natural history of late-life depression: a 6-year prospective study in the community. Arch Gen Psychiatry. 2002;59:605-611.

62. Cui X, Lyness JM, Tang W, et al. Outcomes and predictors of late-life depression trajectories in older primary care patients. Am J Geriatr Psychiatry. 2008;16:406-415.

63. Lyness JM, Chapman BP, McGriff J, et al. Oneyear outcomes of minor and subsyndromal depression in older primary care patients. Int Psychogeriatr. 2009;21:60-68.

64. Hegel MT, Oxman TE, Hull JG, et al. Watchful waiting for minor depression in primary care: remission rates and predictors of improvement. Gen Hosp Psychiatry. 2006;28:205-212.

65. Willemse GR, Smit F, Cuijpers P, et al. Minimal contact psychotherapy for sub-threshold depression in primary care. Randomised trial. Br J Psychiatry. 2004;185:416-421.

66. Wells K, Sherbourne C, Duan N, et al. Quality improvement for depression in primary care: do patients with subthreshold depression benefit in the long run? Am J Psychiatry. 2005;162:1149-1157.

67. Kroenke K. When and how to treat subthreshold depression. JAMA. 2017;317:702-704.

68. Ten Have M, Penninx BWJH, Tuithof M, et al. Duration of major and minor depressive episodes and associated risk indicators in a psychiatric epidemiological cohort study of the general population. Acta Psychiatr Scand. 2017;136:300-312.

69. van Schaik DJ, Klijn AF, van Hout HP, et al. Patients' preferences in the treatment of depressive disorder in primary care. Gen Hosp Psychiatry. 2004;26:184-189. 
70. Mergl R, Henkel V, Allgaier AK, et al. Are treatment preferences relevant in response to serotonergic antidepressants and cognitivebehavioral therapy in depressed primary care patients? Results from randomized controlled trial including a patients' choice arm. Psychother Psychosom. 2011;80:39-47.

71. Samalin L, Genty JB, Boyer L, et al. Shared decision-making: a systematic review focusing on mood disorders. Curr Psychiatry Rep. 2018;20:23.

72. Cuijpers P, Karyotaki E, Pot AM, et al. Managing depression in older age: psychological interventions. Maturitas. 2014;79:160-169.

73. Kirkham JG, Choi N, Seitz DP. Meta-analysisof problem solving therapy for the treatment of major depressive disorder in older adults. Int J Geriatr Psychiatry. 2016;31:526-535.

74. Cuijpers P, Smit F, van Straten A. Psychological treatments of subthreshold depression: a meta-analytic review. Acta Psychiatr Scand. 2007;115:434-441.

75. Cape J, Whittington C, Buszewicz M, et al. Brief psychological therapies for anxiety and depression in primary care: meta-analysis and meta-regression. BMC Med. 2010;8:38.

76. Behnke K, Jensen GS, Graubaum HJ, Gruenwald J. Hypericumperforatum versus fluoxetine in the treatment of mild to moderate depression. Adv Ther. 2002;19:43-52.

77. Rapaport MH, Nierenberg AA, Howland R, et al. The treatment of minor depression with St. John's Wort or citalopram: failure to show benefit over placebo. J Psychiatr Res. 2011;45:931-941.

78. Habicht DW, Witham MD, McMurdo ME. The under-representation of older people in clinical trials: barriers and potential solutions. $J$ Nutr Health Aging. 2008;12:194-196.

79. Cherubini A, Del Signore S, Ouslander J, et al. Fighting against age discrimination in clinical trials. J Am Geriatr Soc. 2010;58:1791-1796.
80. Cherubini A, Oristrell J, Pla X, et al. The persistent exclusion of older subjects from ongoing clinical trials regarding heart failure. Arch Intern Med. 2011;171:550-556.

81. Barbui C, Cipriani A, Patel V, et al. Efficacy of antidepressants and benzodiazepines in minor depression: systematic review and metaanalysis. Br J Psychiatry. 2011;198:11-16.

82. Williams JW Jr, Barrett J, Oxman T, et al. Treatment of dysthymia and minor depression in primary care: a randomized controlled trial in older adults. Jama. 2000;284:1519-1526.

83. Naber D, Bullinger M. Should antidepressants be used in minor depression? Dialogues Clin Neurosci. 2018;20:223-228.

84. Bosanquet K, Adamson J, Atherton K, et al. CollAborative care for Screen-Positive EldeRs with major depression (CASPER plus): a multicentred randomised controlled trial of clinical effectiveness and cost-effectiveness. Health Technol Assess. 2017;21:1-252.

85. Pinquart M, Duberstein PR, Lyness JM. Treatments for later-life depressive conditions: a meta-analytic comparison of pharmacotherapy and psychotherapy. Am J Psychiatry. 2006;163:1493-1501.

86. Ackermann RT, Williams JW Jr. Rational treatment choices for nonmajor depressions in primary care: an evidence-based review. J Gen Intern Med. 2002;17:293-301.

87. Bruce ML, Ten Have TR, Reynolds CF 3rd, et al. Reducing suicidal ideation and depressive symptoms in depressed older primary care patients: a randomized controlled trial. JAMA. 2004;291:1081-1091.

88. Zivin K, Kales HC. Adherence to depression treatment in older adults: a narrative review. Drugs Aging. 2008;25:559-571.

89. Qato DM, Ozenberger K, Olfson M. Prevalence of prescription medications with depression as a potential adverse effect among adults in the United States. Jama. 2018;319:2289-2298.
Neuropsychiatric Disease and Treatment

\section{Publish your work in this journal}

Neuropsychiatric Disease and Treatment is an international, peerreviewed journal of clinical therapeutics and pharmacology focusing on concise rapid reporting of clinical or pre-clinical studies on a range of neuropsychiatric and neurological disorders. This journal is indexed on PubMed Central, the 'PsycINFO' database and CAS, and

\section{Dovepress}

is the official journal of The International Neuropsychiatric Association (INA). The manuscript management system is completely online and includes a very quick and fair peer-review system, which is all easy to use. Visit http://www.dovepress.com/testimonials.php to read real quotes from published authors. 